\title{
L La organización del espacio patagónico: La Iglesia y los planes de evangelización en la Patagonia desde fines del siglo XIX hasta medidos del siglo XX.
}

\author{
María Andrea Nicoletti'
}

\section{Introducción}

La conciencia territorial, desde la presidencia de Sarmiento hasta la de Roca inclusive, emergió ante la problemática que presentaron los espacio "vacíos" o territorios de indios. En el caso de la Patagonia, la ocupación militar fue determinante en la conformación de su estructura social y económica.

Dentro del proceso de avance poblacional, la evangelización de los indios formó parte de las fuerzas "civilizadoras" impulsadas desde el Estado, la Iglesia y la Congregación salesiana. La evangelización bajo los parámetros de "civilización y conversión", cuyo antecedente se remonta a la época colonial, se constituyó en un factor más de ocupación del espacio patagónico. La escasez de presupuesto del Estado Nacional y la falta de clero de la Iglesia local, confluyeron para poner esta tarea en manos de la Congregación Salesiana.

La Congregación Salesiana llegada a la Argentina en 1875 tenía un claro mandato de su fundador Don Bosco: evangelizar la Patagonia. Si bien su idea de "conversión y civilización" coincidió básicamente con la del Estado y la Iglesia nacional, su concepción del indio, su plan y metodología para llevar a cabo la evangelización del "infiel", fueron diferentes e inclusive en muchos casos, contrarios a los de ambas instituciones.

1-Investigadora del CONICET. El presente artículo es un resumen de una investigación llevada a cabo para el CONICET en el año 1997. 
El punto de conflicto entre los Salesianos con el Estado y la Iglesia nacional se presentó en la organización del espacio administrativo de la Patagonia. Nuestro objetivo es analizar qué problemas suscitó la organización del espacio eclesiástico y misionero llevada a cabo por los Salesianos, con el Estado y la Iglesia nacional. La búsqueda de parte de la Congregación Salesiana de una figura administrativa independiente del Estado argentino, como el Vicariato apostólico, avivó la conflictiva relación entre el Estado argentino y el Vaticano. Así, el conflicto acerca del Vicariato apostólico entre la Congregación, el Estado y la Iglesia puso en peligro la permanencia de las misiones salesianas en la Patagonia.

Contrariamente a lo planteado hasta el momento por la historiografía, en especial la salesiana, creemos que la congregación de Don Bosco convirtió aquella posible pérdida de las misiones ante las autoridades argentinas, en una interesante victoria que terminó otorgándoles el territorio de misión a perpetuidad.

Intentando profundizar en las raíces de este conflicto, nuestro trabajo pretende demostrar cómo la concepción misma del plan de evangelización de Don Bosco, que postulaba la idea de libertad y autonomía, trajeron aparejadas enfrentamientos con el Estado y la Iglesia argentina.

Con el fin de desarrollar estas ideas, realizamos una breve reseña del contexto que originó la conciencia territorial en el Estado y la Iglesia argentina. De esta manera podremos comprender los conflictos de poder entre el Estado, la Iglesia y la Congregación salesiana, a través de la organización del espacio eclesiástico en la Patagonia. Finalmente al encontrar las raíces del problema en la concepción de los planes de Don Bosco, concluimos la explicación con el desarrollo de los conceptos que sobre el indio y su territorio tuvieron el salesiano y su congregación.

\section{La conciencia territorial.}

La Argentina que se organiza como Nación desde la sanción de la Constitución Nacional en 1853, tiene pendiente el tema del espacio y los límites interiores como una problemática que coartaba su crecimiento y su desarrollo. El llamado "espacio vacío" (Auza, 1980), considerado así por las instituciones fuera de las fronteras con el indio, refería a una Argentina dentro de otra, cuya frontera fluctuante proyectaba dos ideas distintas de la apropiación de aquellas tierras. La Patagonia y la región chaqueña conformaban por entonces, tierras que superaban en extensión a las regiones pobladas 
por blancos. Este inmenso espacio exterior, poblado por numerosos y variados grupos indígenas, constituyó el desafío más importante del Estado argentino después de la sanción de la Constitución nacional ya que, por un lado, representaba un problema permanente con el vecino país de Chile, y por el otro, significaba para la economía agro-exportadora el freno a la expansión y apropiación de tierras para la agricultura y crianza de ganado.

En realidad la falta de definición provenía del Estado argentino, que tardó en encontrar la forma de incorporar los territorios de indios, pero no de estos últimos que tenían bien en claro que su subsistencia, económica y cultural, dependía de su aislamiento, manteniendo la frontera con el blanco. Si bien hubo un avance de la frontera, escaso durante el período rosista y poco mayor en 1859 - en la frontera norte hasta el río Salado y la frontera sur entre 1862 y 1870-, el espacio "vacío" no parecía ceder y la presión constante del indio a través de la guerra de malones hacían volver la línea de avance prácticamente a su origen.

El poder político no era aún lo suficientemente fuerte ni poseía la convicción necesaria para romper esas fronteras interiores. Con la finalización de los conflictos externos e internos y la solución de la crisis financiera de 1876 se precipitó la decisión de hallar una solución definitiva al problema de los espacios ocupados por los indios.

Durante la época de Sarmiento se insinuaba el cambio que se produjo en forma determinante en la presidencia de Avellaneda a través de una conciencia territorial que se transformó en objetivos claramente políticos. "Ocupar el desierto, como entonces se decía, se convierte en un objetivo compartido por los diversos sectores de la opinión nacional y, además, comienza a pesar sobre la conciencia moral de los hombres públicos. De 1880 en adelante el desarrollo de ese impulso, el crecimiento de esa energía parece imposible de detener, fortalecida por el éxito obtenido en los últimos cuatro años. Se daba la convergencia de ese fuerte espíritu moral con una relativa esclarecida conciencia territorial que ponía en marcha la voluntad nacional para recuperar para la nación y para siempre, el pleno goce y ejercicio de la soberanía sobre todo el territorio". (Auza, 1979:13)

La conciencia territorial fue personificándose en importantes agentes internos pertenecientes a la ciencia y a la literatura ${ }^{2}$, pero las apetencias y avances

2- Auza menciona agentes internos y factores externos como elementos conformadores de la conciencia territorial. Entre los agentes internos destaca a los exploradores, las Instituciones como la Sociedad Científica Argentina (1876) y el Instituto geográfico Argentino (1879) -que fueron también expresiones de la conciencia nacional y territorial promovidas por Estanislao Zeballos y Francisco P. Moreno respectivamente- $y$, en tercer lugar, a la literatura que contribuyó significativamente. 
de los países vecinos en nuestras fronteras fueron el factor externo desencadenante de la ocupación del "espacio vacío". La política de Avellaneda en su conjunto buscó hacer carne esta conciencia territorial en campañas concretas de avances de frontera a través del Ministro Alsina inicialmente (1876-77) y luego con Roca (1878-79) como Ministro y como presidente.

La ocupación del espacio y la conciencia territorial contenían a su vez, una arrolladora fuerza cultural y poblacional que colaboró en la conformación de la sociedad. Dentro del proceso de avance y poblamiento, la evangelización surgió como una fuerza "civilizadora" inicialmente desde el mismo estado nacional que repitiendo los antecedentes hispanos de "civilización y conversión" tomó a la Iglesia como factor ocupacional de territorios poblados por "infieles".

En 1873 el Ministro Nicolás Avellaneda presentó al poder legislativo un proyecto que buscaba hacer cumplir el artículo de la Constitución, por el cual el Congreso debía conservar el trato pacífico con los indios y promover su conversión al catolicismo a través de una comisión presidida por el Arzobispo Aneiros. La preocupación por articular y promover la evangelización en la Patagonia de parte del poder estatal aparece mencionada en las Memorias del Ministerio del Interior bajo dos aspectos básicos: el nombramiento de sacerdotes y capellanes y la formación de reducciones.

El nombramiento de capellanes fue realizado de acuerdo al ejercicio del patronato, por decreto del presidente con recomendación eclesiástica ${ }^{3}$. En lo que respecta a las reducciones y colonias indígenas, el Estado previó una legislación especial "creando con autorización del Poder Ejecutivo las misiones que sean necesarias para atraerlos gradualmente a la vida civilizada"4.

Aunque la legislación citada no se cumplió en la Patagonia aparecía claramente como deber estatal la promoción de misiones para la "civilización". La Dirección General de Territorios Nacionales a cargo del trato con los indios concentró en el departamento de Interior todo lo "referente a la incorporación de los indios a la civilización del país de conformidad con la ley de organización de los Ministerios"s.

El Ministerio del Interior se ocupó entonces del problema indígena a fin de

3-ARCHIVO GENERAL DE LA NACIÓN, Ministerio del Interior, legajo 14 exp.5698. En adelante AGN.

4-TERRITORIOS NACIONALES. Leyes y decretos sobre su administración y resoluciones varias aplicables en los mismos. Buenos Aires, 1914. Ley 1532 sobre organización de los Territorios Nacionales, art.6 Atribuciones del Gobernador, inc.11, p.34.

5-Idem art. 18 inc. 12 p. 236. 
"incorporar la raza india a las razas de una ética superior que forman la Nación Argentina." A diferencia de la gestión de Avellaneda que incluía a la Iglesia en las reducciones como brazo ejecutor de las mismas, bajo la presidencia de Roque Sáenz Peña, las misiones tuvieron un carácter civil ya que "se ha ensayado el sistema de la reducción militar después el de la misión religiosa y últimamente se ha entregado a una Comisión financiera civil todo lo referente a los indígenas en la reducción de Napalpí (Chaco)". Un avance más realizó el Ministerio del Interior al conformar una Comisión honoraria de reducciones de indios que involucró, definitivamente, a las reducciones religiosas dentro de la órbita de sus resoluciones legales si es que ellas recibían aportes del Estado.

Las memorias del Ministerio del Interior nos demuestran que estas reducciones civiles se aplicaron fundamentalmente en los territorios del norte del país. En el sur, la llegada de los Salesianos modificó profundamente la situación de los indios y la administración eclesiástica de los territorios nacionales. Los gobiernos nacionales de Roca en adelante, conscientes de su escaso presupuesto, de la falta de clero secular y de la escasa disponibilidad de funcionarios públicos, no estuvieron dispuestos a sacrificarlos en favor de varios centenares de sobrevivientes. El Arzobispado de Buenos Aires, que tenía jurisdicción sobre la Patagonia desde 1897 se encontraba como toda la Iglesia en una situación de inferioridad por las relaciones interrumpidas con la Santa Sede y de debilidad ante los ataques de liberales y masones. En el orden práctico, no podía llegar a territorios tan vastos y distantes con un clero escaso y sin instrucción en la difícil tarea de la "propagación de la fe".

\section{La organización eclesiástica del espacio patagónico: conflictos de poder.}

La obra misionera para la evangelización de los indígenas sureños, tanto desde el Arzobispado porteño como desde la Congregación salesiana precedió a la división eclesiástico-administrativa de los territorios patagónicos.

Si nos circunscribimos a lo estrictamente jurisdiccional, la Patagonia fue incorporada como territorio nacional a partir de las campañas militares,

6-MEMORIAS DEL MINISTERIO DEL INTERIOR, 1912-13.Informe de la Dirección General de Territorios Nacionales. p.99.

7- Idem.p.110. Se refiere a la reducción del Chaco de Napalpi que sirvió como modelo para las restantes. Las normas de dicha reducción se encuentran en las Memorias citadas y son los decretos del Presidente Sáenz Peña del 24 de julio de 1912 y del 26 de agosto de 1912. 
perteneciendo eclesiásticamente a la Arquidiócesis de Buenos Aires.

La entrada de los misioneros inmediata a las campañas de 1879 , comenzó a configurar un mapa de misiones y parroquias previo a la división administrativa. La acción salesiana se fue extendiendo a medida que se iban creando jurisdicciones eclesiásticas. El Arzobispo Aneiros entregó a los salesianos la parroquia de Carmen de Patagones en 1879, a cargo de M. Fagnano desde 1880. Esta primera misión patagónica, que había pertenecido a los padres lazaristas, abarcaba las poblaciones de: Guardia Mitre, Conesa y Choele Choel. Viedma fue constituida como parroquia el 24 de abril de 1880 y sus primeros párrocos fueron el padre Rizzo y el padre Milanesio sucesivamente.

En tanto se constituían estos centros neurálgicos de misión, el fundador de la Congregación Salesiana, Don Bosco, seguía adelante con su plan de obtener de la Santa Sede, la erección de un Vicariato apostólico y una Prefectura. Ambos fueron definitivamente erigidos por el Vaticano el 16 de noviembre de 1883. El Vicariato apostólico abarcaba: la Patagonia Septentrional y Central (Neuquén, Río Negro y Chubut) y la Prefectura apostólica incluía a: Santa Cruz, Tierras del Fuego, Islas Malvinas e islas del Atlántico sur. Para ello fueron nombrados los Salesianos Juan Cagliero, Obispo de Mágida y Monseñor José Fagnano respectivamente, sin embargo ni dichas divisiones eclesiásticas ni sus cabezas fueron reconocidas por el gobierno argentino.

El Obispo Juan Cagliero llegó a la Patagonia en 1885 iniciando él mismo las giras apostólicas. Los centros misioneros a lo largo del Río Negro y del Río Colorado habían sido ya afianzados, por lo tanto, los Salesianos buscaron comunicar la costa atlántica con la cordillera atravesándola en distintas ocasiones. Cuando el Obispo Cagliero y sus misioneros se encontraban organizando sus giras y núcleos de misión, desde el Arzobispado de Buenos Aires se nombró a Francisco Vivaldi, el $1^{\circ}$ de enero de 1884, como párroco de Rawson, desatando así una larga e intrincada discusión sobre superposición de poderes con el Vicariato apostólico, erección que el Arzobispo de Buenos Aires conocía pero no reconocía.

Con este nombramiento se presentaban dos cuestiones problemáticas: una de ellas era la jurisdicción de poderes en "territorio salesiano" y la otra estaba relacionada con la conducta personal de Vivaldi ${ }^{8}$.

8-Francisco Vivaldi nació en Niza el 12 de enero de 1824. Se desempeñó como cura en Ventimiglia. En 1851 viajó con Monseñor Crétin a Minnesotta, estados Unidos donde había sido designado. Su tarea allí fue evangelizar a los indios y fundar una congregación de hermanas del "amor de Dios", estas tareas se complicaron por una fuerte deuda que contrajo Vivaldi y que le trajo aparejado el enojo del Obispo. Vivaldi decide abandonar la diócesis y el sacerdocio, viaja a Milwake y se une alli a una viuda rica. En Manhattan (Kansas) llegó a ser redactor de un periódico y alcalde del pueblo. 
Para evitar problemas con el gobierno, el Arzobispo de Buenos Aires mantuvo oculto el nombramiento del Obispo Cagliero. Esta situación ambigua fue "aprovechada" por el Arzobispo Aneiros, ya que mientras aconsejaba al Obispo salesiano mantener su nombramiento en secreto dispuso de la jurisdicción diocesana anterior en forma completa. La comunicación oficial de la erección del Vicariato no había llegado a manos del Arzobispo, aunque éste la conocía extraoficialmente a través del Prefecto Cardenal Simeoni ${ }^{9}$, Juan Cagliero y el mismísimo Don Bosco. En esto se respaldaba Aneiros, que no se oponía al nombramiento de $\mathrm{M}$. Cagliero como vicario apostólico mientras él y el gobierno reconocieran oficialmente la situación. Además, al saber que el gobierno, por su postura anticlerical, la rechazaría, fue una razón más para dilatar y desconocer los acontecimientos

En 1886, Vivaldi fundó una pequeña capilla en Rawson denominada Nuestra Señora de Lourdes del Chubut y en 1889 inició el proyecto de evangelización de los tehuelches en Paso de los Indios. Solicitó tierras al gobierno que le fueron concedidas el 3 de enero de 1890 con el fin de fundar allí una misión católica para reducir a las tribus de Chiquichano, Inacayal y Foyel. Pero se dio cuenta que la tarea era realmente vasta y que necesitaba misioneros para llevarla a cabo. No quería llamar a los Salesianos, pues esto representaba admitir su poder en una jurisdicción que le era propia. Debió por lo tanto, encontrar misioneros para llevar a Paso de Indios, aunque Monseñor Espinosa, vicario del Arzobispo, le indicó el establecimiento de una congregación que se ocupa del cultivo de las tierras con la que podía ponerse en contacto, refiriendose así, a los Salesianos.(Copello, 1944:72) De esta manera, el Arzobispado confirmaba el conocimiento pleno de los objetivos de la Congregación Salesiana en la Patagonia.

Entusiasta y ambicioso, Vivaldi pretendió ser nombrado Vicario del Chubut, por lo que viajó a Roma a fin de iniciar los trámites. En dos entrevistas con el Procurador le expuso el beneficio de la erección del Vicariato en Chubut, convenciéndolo de la solicitud del arzobispo y del aporte económico que el Estado argentino otorgaba a dichas misiones, argumentando además, que se podrían

Su periódico apoyaba la elección de Lincoln y esto le facilitó la designación como cónsul efectivo en Santos (Brasil) hasta 1869. De allí se fue a Río de Janeiro donde fundó tres periódicos. Tuvo una hija Corina, también periodista, casada con el escritor brasileño Visconti Coiazi. Mientras tanto, deja en el Chubut una misión a medio hacer en Paso de los Indios y cuantiosas deudas. Nunca más volvió allí e incluso se le dio por fallecido mientras estaba retirado en París. Murió en el asilo de las Hermanas de San Vicente de Paul el 15 de enero de 1902.

9-Cardenal Juan Simeoni, Prefecto de la Sagrada Congregación de Propaganda Fide. Encargado de los asuntos correspondientes a la propagación de la fe católica. 
aplacar los enojos del gobierno civil y eclesiástico por haber otorgado un Vicariato a los Salesianos sin sus consentimientos. El cardenal Simeoni apoyó el proyecto de Vivaldi con entusiasmo ${ }^{10}$. Mientras tanto, los Salesianos se enteraban a través de César Cagliero, primo de Juan Cagliero y procurador salesiano en Roma, de este proyecto e instaron a Don Rúa " a escribirle al Papa. Este último, le objetó duramente que "Si Vuestra Santidad no pone remedio, el canónigo Vivaldi conseguirá remover el yugo de la obediencia, y coronar con todo éxito los designios de insubordinación al Vicario apostólico, su inmediato superior, y a la misma Santa Sede, que confió todas aquellas regiones a la atención de los Salesianos" ${ }^{\prime 2}$.

Circunstancias fortuitas encajonaron el proyecto. En 1892 el cardenal Simeoni falleció, los objetables antecedentes de Vivaldi habían demorado los papeles prudentemente, y éste no intentó volver a la Argentina, abandonando así la misión iniciada con los tehuelches, que continuó el padre salesiano Bernardo Vacchina en 1891.

La división de Obispados del 15 de febrero de 1897 dio una nueva organización eclesiástica al país, incluyendo a los territorios nacionales pertenecientes a la Vicaria y Prefectura apostólica confiada a los Salesianos. La nueva ley de diócesis del 25-11-1887 solicitó la erección de las nuevas diócesis de La Plata, Santa Fe y Tucumán, y en lo que respecta a los territorios federales, la "determinación de las diócesis en que deban ser comprendidos" ${ }^{13}$. El cometido de aprobación de la ley ante la Santa Sede estuvo a cargo de Milcíades Echagüe que "no consiguió que la misión llegara a buen término" 4 hasta 1896 y 1897 bajo la presidencia de Uriburu.

La misión Calvo ${ }^{15}$ fue la encargada de definir finalmente la situación. Las cartas al Cardenal Rampolla ${ }^{16}$ manifestaban el desconocimiento que sin duda

10. Según interpreta Cayetano Bruno, la idea de Vivaldi facilitaba al Cardenal un proyecto misionero que no se había podido concretar. Simeoni pretendía establecer en Manchuria una misión con sacerdotes del seminario Santos Pedro y Pablo, pero el Vicario de Manchuria se negaba a desmembrar su vicariato. Esta pues representaba una excelente ocasión para enviar a este grupo al Chubut.

11- Salesiano, sucesor de Don Bosco en el cargo de Rector mayor de la Congregación.

12-Carta enviada al Papa, fechada en Turin el 14 de diciembre de 1891, cit. en (Bruno, 1981:428)

13-ARCHIVO DEL MINISTERIO DE RELACIONES EXTERIORES Y CULTO, Caja 310, Culto. Antecedentes y resoluciones sobre Culto. En adelante AMREC.

14- AMREC, caja 18 (640). Culto.1897. Leg.3. Carta al Cardenal Rampolla, secretario de Estado de la Santa Sede de Carlos Calvo. Roma, diciembre 7 de 1896.

15- Carlos Calvo, embajador argentino en Berlín, era una persona que gozaba de alta estima en la Santa Sede, aunque era reconocido como liberal. Por ello, le fue encomendada una misión confidencial ante el papa León XIII, como ministro plenipotenciario argentino, para negociar el restablecimiento de las interrumpidas relaciones entre el Vaticano y nuestro país.

16-Mariano Rampolla del Tíndaro, secretario de Estado del Papa León XIII. 
no era tal, de la existencia del Vicariato y de la Prefectura en la Patagonia. El gobierno no reconocía la erección eclesiástica patagónica hecha en 1883 por la Santa Sede ${ }^{17}$. Sin embargo, Calvo dejó una interesante puerta abierta que ayudó a los Salesianos a intentar nuevamente la legitimación del Vicariato, manifestando que "si por parte de la Santa Sede se juzgase que convendría hacer divisiones distintas a las autorizadas por la ley mencionada, el abajo firmado se apresuraría a transmitir a su gobierno las bases para la nueva demarcación de los Obispados, pidiendo las instrucciones del caso." "18

En este sentido ni la Santa Sede ni la Congregación se hicieron esperar, el mismo Cardenal Rampolla quiso conocer la opinión de Monseñor Cagliero al respecto que después de un exhaustivo informe le ofreció al cardenal tres posibilidades concretas: el reconocimiento final del Vicariato y la Prefectura, que era obviamente la de su preferencia; la erección de una nueva diócesis, o la creación de dos auxiliares para el Obispo de La Plata con residencia en Tierra del Fuego y en Río Negro.

La posición que la Santa Sede debía tomar significaba llevar a buen puerto las inminentes relaciones diplomáticas con la Argentina, y preservarle a la Congregación Salesiana el territorio que ellos mismos le habían concedido. La solución no era sencilla y cada parte presionaba por su lado. El parecer de Monseñor Cagliero fue categórico y la negativa del gobierno argentino del reconocimiento del Vicariato también fue sumamente elocuente.

El consultor de la Sagrada Congregación de Negocios eclesiásticos evaluó el parecer de Monseñor Cagliero como más convincente para el reconocimiento del Vicariato, pero se sumaba a ello otro problema que el mismo gobierno manifestaba: las distancias con los centros poblados y la extensión del territorio patagónico. Este argumento no favorecía la posición del gobierno de hacer depender a un territorio tan extenso de una sede lejana y contrariaba sus principios con la nueva división eclesiástica que anexaba el territorio patagónico a la Arquidiócesis de Buenos Aires a cambio de la ciudad de La Plata.

La fórmula de conciliación que resultó finalmente como la más propicia para la Santa Sede fue la siguiente: el Vicariato y la Prefectura quedarían bajo el gobierno efectivo e independiente de la Congregación Salesiana y bajo la jurisdicción de la Arquidiócesis de Buenos Aires. La Santa Sede de todos modos, explicó al gobierno argentino que se debían dejar a salvo los derechos de los misioneros Salesianos en la Arquidiócesis, mencionando expresamente las divisiones del Vicariato y la Prefectura. Carlos Calvo consciente de la

17-Idem.

18-Idem.

- Instituto de Historia Regional - Facultad de Ciencias Humanas - Universidad Nacional de La Pampa - 
situación y midiendo sus palabras garantizaba que va a transmitir al gobierno "dichos derechos adquiridos por los misioneros Salesianos". La palabra Vicariato parecía estar prohibida en el lenguaje diplomático ${ }^{19}$, pero la explícita mención de "derechos adquiridos" legítima la situación de la Congregación en la Patagonia.

Finalmente la bula ereccional de 1897 expedida por León XIII modificó el mapa eclesiástico de la Patagonia incorporando a la Arquidiócesis de Buenos Aires, la Capital Federal y los territorios de Río Negro, Chubut, Santa Cruz, Tierra del Fuego e isla de los Estados; mientras que a la Diócesis de La Plata quedaban incorporadas la provincia de Buenos Aires y el Territorio de La Pampa, y finalmente a la Diócesis de Cuyo, el Territorio del Neuquén. ${ }^{20}$

Los Salesianos quedaban nuevamente a medias en su cuestión del Vicariato. El inspector salesiano Vespignani opinaba que sin embargo en este auto se había reconocido la existencia del Vicariato aunque sujeto a la evaluación de cada obispo diocesano y a la posibilidad de tener clero propio para estos territorios. Esta posibilidad jugaba en favor de la Congregación y los Salesianos opinaban acertadamente que "aunque no puede determinarse cuando llegará esa época en que haya clero, sin embargo puede asegurarse que esto sucederá cuando esos territorios pasaran a ser diócesis o provincias, ya por su población, sus exigencias sociales, riqueza de sus productos ya por su organización civil. Antes de esa época ningún prelado tendrá sacerdotes argentinos para lanzar a esos desiertos; y cuando llegue la época que la sociedad ya adulta de cada territorio reclame su clero propio, un nuevo obispo tendrá que residir en esas poblaciones para formar su seminario y educar alli mismo un nuevo clero. Antes de esa época no podrá haber sino misioneros." "2" Entretanto la única Congregación que misionaba y preparaba sacerdotes para estos territorios eran los Salesianos, que garantizaban a través de la práctica lo que pretendían alcanzar en los papeles. La clara visión de futuro que presentaba el P. Vespignani no era más que una estrategia que concluyó con el nombramiento de Obispos salesianos cuando las diócesis fueron erigidas definitivamente.

El problema del Vicariato y la Prefectura volvió nuevamente a la discusión

19-AMREC, caja 18 (640). Culto 1897. Correspondencia entre Carlos Calvo y el Cardenal Rampolla.1897. 20- Decreto del Eximo. Gobierno Nacional sobre la erección de las diócesis. Auto de erección de las diócesis firmado por el Arzobispo de Buenos Aires. Uladislao Castellano. AMREC, caja 18 (640).1897. Culto.leg.33 y ACS, Buenos Aires. Caja 152.6. Personas. P.Vespignani. Después de la erección el 15 de febrero de 1897, el cardenal Rampolla le comunicaba el auto de erección al Arzobispo castellano y a Carlos Calvo. Los trámites se cerraron con el pase del presidente Uriburu el 28 de mayo de 1897.

21- ARCHIVO CENTRAL SALESIANO (BUENOS AIRES), Caja 152, Personas, Padre Vespignani, Carta del Padre Vespignani al Internuncio M. Locatelli, 7 de agosto de 1909. En adelante ACS, Bs. As. 
en 1907, cuando el padre Vespignani decidió llevar la cuestión al capítulo superior de la Congregacion en Turín, que examinó pormenorizadamente el tema. Su intención era obviamente defender el proyecto de Don Bosco y que el gobierno argentino lo reconociera, preservando de esta manera la autonomía misionera y sentando las bases para una futura división diocesana. Para ello, el procurador salesiano en Roma junto con el capítulo y el Rector mayor, pusieron a consideración una memoria aprobada por la Congregación de Negocios eclesiásticos que pasó al padre Vespignani para que éste la tratase con el Arzobispo, el Internuncio y el gobierno argentino. ${ }^{22}$

Inmediatamente se consultó al Arzobispo y al Internuncio que vieron imposible el reconocimiento del Vicariato y la Prefectura a causa del patronato. Aún peor resultó la reacción del Ministro Blancas ${ }^{23}$ con el secretario de Estado, el cardenal Merry del Val el 30 de junio de $1909 .{ }^{24}$

La actitud adversa del gobierno y el celo del clero argentino terminó presionando a los Salesianos, que por temor a perder todo, prefirieron negociar con las autoridades gubernamentales. Lo lógico era que el Vicariato y la Prefectura fueran convertidas en diócesis pero en realidad se los bajó de grado transformándolos en Vicarías Foráneas. ${ }^{25}$ Así, mientras la Prefectura apostólica del lado chileno pasaba a ser Vicaría, subiendo de categoría, la del lado argentino descendía a Vicaría foránea. Sin embargo lograron salvar lo más importante: la dependencia salesiana de las tierras de misión.

De esta manera se llegó a un acuerdo por el cual hasta que el territorio fuera erigido como diócesis, las misiones se pondrían bajo la jurisdicción de un inspector salesiano y dependerían del Arzobispo de Buenos Aires, del Obispo de San Juan y del de La Plata respectivamente. Los párrocos y misioneros se nombraban a propuesta del inspector salesiano. Se pidió además que la Santa Sede y los prelados otorgaran a los vicarios foráneos facultades indispensables para atender regiones tan extensas.

La sagrada Congregación consistorial en 1910 a través de un anteproyecto sometido a la consideración de los Arzobispos de Buenos Aires, La Plata y San Juan lo pasó al Papa. Una vez dado el acuerdo de Roma, el Padre Inspector Vespignani lo presentó al presidente Sáenz Peña.

Finalmente, por un auto del 9 de mayo de 1911 se sancionó la nueva entre-

22- ACS, (Buenos Aires) Caja 152.62. P. Vespignani. Memorial sobre Vicariato.

23- Ministro plenipotenciario de la Argentina en Roma.

24-Alegaba los artículos 57 y 86 de la Constitución Nacional respecto de la admisión de nuevas ordenes religiosas en el país, aunque en realidad los Salesianos eran una congregación

25-Tierra del Fuego mantenía eclesiásticamente la división binacional, de tal manera el gobierno chileno decidió subir de categoría su jurisdicción eclesiástica. 
ga de las misiones a los Salesianos definitiva e incondicionalmente ${ }^{26}$ Se dividieron siete vicarías foráneas por la extensión de los territorios. El Arzobispo Espinosa debió nombrar cuatro vicarios en los Territorios de: Río Negro, Chubut, Santa Cruz y Tierra del Fuego, el Obispo de La Plata Terrero dos en Patagones y La Pampa y finalmente el Obispo Orzali de San Juan, al vicario de Neuquén. Todos ellos fueron Salesianos. A pesar del acuerdo, los nombramientos ocasionaron tensiones con los prelados argentinos, que no veían con buenos ojos el poder de la congregación dentro de su diócesis, especialmente Monseñor Terrero.

La dificultad había pasado y los Salesianos lograron mantener el monopolio misionero de la Patagonia. Aún mas, en 1934 fue creada la diócesis de Viedma con jurisdicción hasta Tierra del Fuego; luego en 1957 la diócesis de Comodoro Rivadavia y en 1961, las de Neuquén y Río Gallegos en Santa Cruz, y en ellas, los Obispos nombrados fueron todos Salesianos.

\section{Las raíces del conflicto: los planes misioneros de Don Bosco.}

La configuración del espacio patagónico en la administración eclesiástica tuvo sus bases en los planes concebidos por Don Bosco. Su raíz, en parte conflictiva debido a las circunstancias históricas ya narradas, se encuentra a nuestro entender en la concepción interna del plan para evangelizar la Patagonia.

Don Bosco era consciente que su proyecto para la Patagonia consistía en "la más grande empresa de nuestra Congregación" ${ }^{27}$. Esta primera intuición fue producto de sus "sueños" ${ }^{\text {"28 }}$ que constituyeron el elemento básico de sus planes evangelizadores junto con la información científica sobre la Patagonia y sus habitantes recogida por él.

Entre los recursos pedagógicos que Don Bosco utilizaba con los jóvenes se encontraron las narraciones de sueños personales como parábolas con finalidad pastoral. El historiador salesiano Juan Belza advierte respecto de los sueños misioneros-geográficos, "que todos sus detalles responden históricamente a conocimientos e informaciones preexistentes en la memoria consciente o inconsciente de Don Bosco, movilizado por sus ansias misioneras." (Belza,

\section{6-ACS, Caja 59, Monseñor Espinosa. Auto del 9 de mayo de 1911.}

27- EPISTOLARIO DI S.GIOVANNI. BOSCO T. IV, 214, Carta de San Juan Bosco a Don Fagnano, Turín 31 de enero de 1881.

28- Los "sueños" denominados asi por el mismo Don Bosco, han sido visiones sobre lugares o personas. Para la Patagonia consideramos dos sueños narrados en 1876 y 1883 a sus religiosos. En ellos Don Bosco contempló su obra misionera en América, el Vicariato y Prefectura a cargo del Obispo Cagliero, las riquezas y geografia americanas con sus ciudades no fundadas en ese momento y la obra salesiana. 
1979:25) Estas imágenes se fueron forjando en su mente a medida que acumulaba conocimientos sobre el territorio patagónico. Desde el sueño de 1872, narrado recién en $1876{ }^{29}$, Don Bosco sintió el impulso de llevar el Evangelio a tierras de infieles, sin advertir de qué lugar se trataba. Recién en 1874, cuando inició conversaciones con el cónsul argentino en Savona, pensó en la Patagonia. "Al instante agencié unas geografías de la América del Sur y las leí atentamente. ¡Cosa estupenda! En ellas y en los grabados que las ilustraban vi perfectamente descritos los salvajes vistos en el sueño y la región por ellos habitada, la inmensa Patagonia, extendida al mediodía de aquella República" (Bosco, 1876, -1996:23-)

Los "sueños" o visiones tuvieron una profunda repercusión en los planes misioneros y fueron la llave para que Don Bosco investigara sobre aquellas tierras desconocidas y sus habitantes. Por lo tanto podemos afirmar que ambos aspectos, los "sueños" o visiones y la información científica, se han cristalizado tanto en la concepción interna del plan misionero (idea de conversión del indio), como en el aspecto externo de dicho plan (organización administrativa del espacio misionero en un Vicariato apostólico). Pasaremos a explicar esta afirmación.

Para la concepción del plan de conversión del indio, debió existir antes una "idea o imagen del indio patagónico". Don Bosco se basó fundamentalmente en los estudios de d'Orbigny, para analizar las costumbres de los indígenas en relación al carácter ${ }^{30}$ de los pueblos. Las descripciones geográficas y del hábitat patagónico mantienen este mismo sentido que en la obra del mencionado autor.

29-"Existen por lo menos dos relatos de dicho sueño. Don Bosco se lo narró a Pío IX en abril de 1876, a fin de julio de ese año se lo contó a Don Bodratto que a su vez lo narró a Don Barberis. Tres años después el mismo Don Bosco se lo cuenta a Barberis que lo escribe. En 1884 Don Lemoyne juntando datos sobre Don Bosco hace una nueva redacción en la que presenta un recuento histórico de como este sueño influyó en la elección de la Patagonia y en la primer misión salesiana.". (Da Silva Ferreira, 1996: 109,110)

30-Para d'Orbigny el carácter de un pueblo tiene un origen común inmutable y transmisible. En el concepto romántico de carácter nacional la forma de ser de un pueblo y esta determinado por la geografia, la economía y las características fisicas de un pueblo. "Aunque el carácter del hombre varíe mucho con los individuos, no puede negarse que existen matices debidos al origen común. Al juzgar una nación o una raza en su conjunto, comparada a otra podrá comprobarse que una tiende hacia la dulzura y otra hacia la ferocidad...orgullosos e indomables guerreros, los pueblos más meridionales de las montañas y mesetas, los Araucanos, Patagones, Puelches, Charrúas, Mocobis, etc, combatieron encarnizadamente a los espantoles cuando estos llegaron, y, al cabo de tres siglos prefieren dejarse diezmar sin cesar por los españoles, a reconocer sus leyes y religión.... ¿no demostrará evidentemente que cada raza y cada nación pueden tener en el carácter matices que, sin cambiar jamás, parecen perpetuarse de generación en generación, en los miembros del mismo pueblo?..." (d'ORBIGNY, 1944:119) 
En su conceptualización general sobre el indio patagónico, la característica permanente de primitivismo coincide con la de d'Orbigny pero existía una diferencia substancial entre ambos. Aunque Don Bosco siguió la descripción científica de los estudios de d'Orbigny va más allá de ellos, porque su espíritu misionero y su profunda fe pusieron en cuestión lo que para d'Orbigny era irreversible: la posibilidad de "civilizar" a los pueblos libres al afirmar que "este pueblo es apto para la civilización." (Bosco, 1876, -1996:79)

Para Don Bosco había una posibilidad y un camino para estos hombres: la luz del Evangelio. Los misioneros son los instrumentos para lograrlo pues "sólo el misionero, con su conducta de paz, podría poco a poco hacer deponer el odio que se tiene contra todo lo que sabe europeo, y junto con la religión, introducir la civilización en aquellos países" (Bosco, 1876, -1996:78)

Don Bosco entendía que el problema de la barbarie del indio patagónico tenía dos componentes, a nuestro entender, esenciales. El primero, de carácter natural: el primitivismo y la barbarie, tomado de d'Orbigny, que se modificaría de acuerdo a su criterio con la educación. El otro, de índole sobrenatural, cuya raíz es la negación al cristianismo a través de Satanás, se presenta como una continuidad de las ideas jesuitas sobre la demonización en los indios: El demonio impide u obstaculiza la conversión a la Fe por mantener al indio en las tinieblas y en la ignorancia. De esto el indio no es culpable sino una víctima. (Nicoletti, 1994)

La conclusión por tanto es que el indio es un infiel, desconocedor de la verdad por ignorancia, "que no ha recibido nada de la luz del Evangelio, o sino que una vez recibida esta luz, han sido casi todos abandonados...porque están aún casi totalmente en las tinieblas del error y de la barbarie". (Bosco, 1876, 1996:75) Esta ignorancia, no falta de inteligencia ${ }^{31}$, los hace "muy inclinados a la magia y la superstición." (Bosco, 1876, -1996:793-) Romper esa barrera y atraerlos al Evangelio era, para Don Bosco, el único camino posible.

Las conclusiones de Don Bosco en su trabajo de investigación conformaron la síntesis de una imagen previa del indio patagónico, transmitida a sus misioneros: "Dos pensamientos sirven de conclusión. iEl primero es muy doloroso! ¿Y quién hay que no se entristezca al ver varios millones de hombres aún totalmente ignorantes del cristianismo, de toda idea de religión y de moralidad, yacer en las sombras de la muerte? „Ellos no saben y ni siquiera se les ocurre pensar que Jesucristo, Dios eterno como el Padre, haya venido a hacerse hombre y a morir para salvarnos de la esclavitud del demonio y del pecado!

" 31-"Los patagones- añade d'Orbigny- no carecen de inteligencia, y su índole nacional merece ser tenida en cuenta". (Bosco, 1876, -1996:85-) 
Ellos no tienen ni civilización, ni gobierno, ni industria, ni agricultura, ni comercio; los litigios los resuelven a fuerza bruta, $y$ el derecho es reconocido a quien es más fuerte y más astuto. Tienen predilección por los saqueos y robos, y dejan morir bárbaramente a los niños que no quieren educar. No tienen idea del matrimonio y admiten la poligamia y también la poliandria. Guerrean, matan, degüellan continuamente. Muchas veces comen también carne humana... ¿Podría un corazón cristiano permanecer frío ante semejantes consideraciones?

Más si este pensamiento es tan doloroso y oprimente, otro y muy consolador comienza a asomar a nuestra mente, y a quitar la angustia dejada por el primero. Si, parece llegado el tiempo de la Divina Misericordia para esas vastísimas tierras. Es la bondad de Dios, que quiere liberar a esos pueblos de la dura esclavitud de Satanás... Quiera Dios que la Congregación Salesiana tenga la dicha de poder participar aunque sea un poco de esta obra providencial; a ella se unan otros y otros misioneros y religiosos, los que todos con un solo corazón y una sola alma trabajen por la evangelización de los pamperos y de los patagones... esta empresa tendrá un seguro presagio de éxito, si la Sagrada Congregación De Propaganda Fide se digna tomar bajo su eficaz protección al proyecto presentado; examinarlo, modificarlo y con sus santos e iluminados consejos orientar a quienes de buena gana se ofrecen para trabajar, si no con mucha ciencia y virtud, ciertamente con buena voluntad, y con el ánimo dispuesto a cualquier sacrificio de que ello dependa. Soli Deo honor et gloria. Amen. Turín, 20 de agosto de 1876"(Bosco, 1876, -1996:7112-)

Don Bosco expresaba claramente que era la falta de civilización por un lado, y por el otro, la esclavitud del demonio, los elementos que hacían del indio un ignorante de la $\mathrm{Fe}$. Las posibilidades de redención estaban claramente enunciadas: Dios a través de la Congregación salesiana podía proveer misioneros que siguiendo el plan presentado, evangelizaran para lograr una verdadera conversión como única posibilidad de salvación de sus almas.

A los misioneros les había sido transmitida esta imagen del indio: ${ }^{32}$ la de un salvaje cuya única posibilidad de civilizarse era abrazar la fe, y aunque la realidad circundante modificó en parte esa imagen previa elaborada por Don Bosco, ésta permaneció intacta en su esencia cuando se construyó un plan misionero "evangelizador y civilizador" del indio. En conclusión, esta imagen previa del indio infiel fue el soporte que diseñó el plan de evangelización en base a la "civilización y conversión" simultánea del indio. Las metodologías

32-EI análisis del "imaginario de la Evangelización" fue desarrollado en los informes al CONICET, (Nicoletti, 1993-95,1996,1997) 
fueron ideadas y puestas en práctica por los misioneros que nunca abandonaron esta imagen previa transmitida por Don Bosco.

Hemos señalado brevemente dentro del plan misionero gestado por Don Bosco, los elementos que colaboraron en la idea específica sobre el modo de "conversión" que debía llevarse a cabo en la Patagonia. Nos referiremos ahora al plan de misión desde el punto de vista de la organización administrativa, base de la Iglesia patagónica que concibió Don Bosco, como ya señalamos desde sus visiones y su concepción científica.

En primer lugar, debemos señalar la dificultad para comprender la magnitud de un territorio de las dimensiones del patagónico. Don Bosco sólo aventuraba conjeturas sobre este espacio que nos demuestran la dificultad de comprensión de la vastedad del territorio: "Al sur de Chile y de la República Argentina yacen, casi desconocidas, las Pampas, la Patagonia y las Tierras del fuego. Estas regiones vastísimas de América del Sud constituyen el terreno continental más austral del globo. Situadas en el extremo del Nuevo Mundo, en un clima inhóspito, sólo ha sido explorada una mínima parte de las mismas. Por esta razón, dichas tierras permanecen todavía envueltas en un misterio...de esta manera estamos reducidos ahora a vagas conjeturas, en particular sobre el centro de la Patagonia del que se puede afirmar que es totalmente desconocido y al que los geógrafos se ven obligados a presentar en blanco aún en los mapas más detallados. "(Bosco, 1876, -1996:49-)

El desconocimiento es grande, entre otras cosas porque el mismo Estado argentino sólo sabía por aproximación el número de indios que habitaban la Patagonia, y las conjeturas son completamente erróneas, por desconocimiento de las condiciones ambientales y del modo de vida de los pueblos indios.

"Es imposible calcular con exactitud el número de habitantes de estas regiones...lo que se puede decir de más cierto es que cuanto más se estudia, más uno piensa que el número de sus habitantes es grande...lo que más fundamenta el gran número de indios que pueblan los confines del territorio de la República Argentina y de Chile, es que a pesar de los esfuerzos de los gobiernos de Buenos Aires y de Santiago, no se ha podido someter aún a esas tribus, que muchas veces consiguen importantes triunfos sobre los blancos"... "¿Cómo ocurriría esto, si aquellos no fuesen extraordinariamente numerosos?"... "Ahora bien, la Patagonia con las islas y las pampas adyacentes, que se extienden sin interrupción hasta el Ecuador, es vasta como Europa ¿Qué población no podríamos calcular en tanta extensión, considerando que hay tribus tan numerosas en los confines?...suponiendo que se estime globalmente que esas regiones están habitadas diez veces menos que en Italia, yo hallaría todavía 
cerca de 40 millones de habitantes entre la Patagonia y las pampas. Se dirá que este número es evidentemente exagerado. Bien, supongamos que sólo sea la mitad, sólo una tercera parte, aún solo una décima parte y yo encontraré todavía cerca de cuatro millones de indígenas, lo que supera inmensamente todo lo que se puede escribir en los libros de geografía y de viajes" (Bosco, 1876, -1996:109-)

Por lo tanto, las divisiones administrativas y los planes de centros de misión fueron tentativos en principio hasta tanto los misioneros pudieron entrar a la Patagonia y transmitirle a Don Bosco una idea más clara sobre las dimensiones del territorio: "Parece increible! El Vicariato de M. Cagliero abraza una extensión igual a la de Francia, España y casi toda Italia. Quien no quiera creerlo venga a medirlo" ${ }^{33}$ manifestaba uno de sus misioneros.

Inicialmente existió un proyecto de establecer una colonia italiana en la Patagonia atendida por los Salesianos (Da Silva Ferreira, 1975: 14), a la que Don Bosco imaginaba como puerta de entrada para la evangelización de los indios. En sus escritos Don Bosco planteaba tres proyectos posibles: "Primero de todo, el Arzobispo de Buenos Aires propone confiar a la congregación salesiana la última parroquia de su vastísima arquidiócesis, en los confines de la Patagonia...instalado así un centro sobre los confines septentrionales, se podrá luego con facilidad internarse en la Patagonia desde aquella parte. Este es el pensamiento que con su carta del 1 de julio manifestó M. Federico Aneiros, Arzobispo de Buenos Aires"... "El segundo proyecto ofrece también él fundadas esperanzas. Habiendo oído hablar favorablemente de los misioneros Salesianos, dos caciques de los más influyentes fueron a rogar a D. Cagliero que les mandase misioneros a explicarles la religión de los cristianos, prometiendo escucharlos con docilidad y suministrarles todo lo necesario"...haciéndonos amigos de estas dos tribus podremos abrirnos camino por toda la Patagonia"... "Un tercer proyecto viene a abrir un nuevo camino para la conversión de la Patagonia. El gobierno argentino quiere establecer una colonia en un punto muy distante de los precitados y confiaría la dirección a los Salesianos. Esta colonia se debe fundar en Sta. Cruz que es un puerto con un río ubicado muy dentro de la Patagonia sobre la costa del Océano Atlántico" (Bosco, 1876, 1996:111-)

Sabemos que el proyecto que finalmente se concretó fue el primero, con el ofrecimiento de Carmen de Patagones como misión de parte del Arzobispado. Don Bosco tenía claros sus objetivos de conversión de la Patagonia entera y pensó en un proyecto más abarcador que Carmen de Patagones, especulando

33- En Boletin salesiano, julio 1890.

- Instituto de Historia Regional - Facultad de Ciencias Humanas - Universidad Nacional de La Pampa - 
con la necesidad de misioneros en tierras inhóspitas y vastas. Fue entonces cuando surgió la idea de crear una jurisdicción eclesiástica que le diera suficiente libertad de movimiento a su congregación respecto de la Iglesia Nacional, la cual inevitablemente era dependiente del Estado Argentino. La instauración de una Vicaria apostólica ${ }^{34}$ resumía todas estas posibilidades, ya que:

1) Debía ser designada directamente por la Santa Sede. Factor esencial para las enormes distancias entre Europa y la Patagonia sobre todo a fines del siglo XIX. Esto le permitiría a Don Bosco gestionar personalmente el trámite en el Vaticano con el Papa y mantener las jurisdicciones de sus misiones en manos de Roma y no en manos del estado argentino.

2) Era una jurisdicción ordinaria para regir las cristiandades en territorios donde aún no había sido introducida la jerarquía eclesiástica. Este punto era fundamental para la Congregación Salesiana que se introducía en territorio virgen, sin sacerdotes y sin ninguna otra orden o congregación religiosa. De esta manera ellos mismos tenían la posibilidad de establecer su propia jerarquía eclesiástica.

3) Solían estar gobernadas por un Obispo titular. Esta fue la gran oportunidad de Don Bosco para hacer nombrar a su primer Obispo salesiano, al más apto y a quién había elegido desde aquel sueño de 1872 para aquella tarea: Juan Cagliero.

Todas estas razones de clara influencia en la génesis de la Iglesia patagónica fueron pensadas y elaboradas por Don Bosco que, inmediatamente, se las comunicó al Papa: "se concluye que es necesario un Vicariato apostólico con sede en la colonia que ha sido constituida sobre la costa del Río Negro y un seminario en Europa que provea obreros para evangelizar ${ }^{\prime 35}$

Don Bosco aceptó rápidamente el ofrecimiento de $\mathrm{M}$. Aneiros pero lo hizo a partir de su propuesta de trabajo misionero, elaborada como señalamos, en un marco administrativo con forma de Vicariato, la cual ya había sido consultado previamente con el Papa: "considerando la distancia de las colonias del Río Negro a la sede arzobispal (quince días de viaje) propone (el Papa) la creación de un Vicariato Apostólico, el cual abarcaría las poblaciones establecidas y las que se vayan formando sobre las riberas del Río Negro". Se denominaría Vicariato apostólico de la Patagonia siendo así llamada la fracción

34- En la nomenclatura canónico-eclesiástica la creación de un Vicariato es la segunda etapa en orden al gobierno de lugares de misión, la Prefectura es el primer paso y la diócesis el tercero. El Vicariato era presidido por un Obispo mientras que la Prefectura no.

35-Memorias biográficas de San Juan Bosco, vol. XIV.p.623. Carta de Don Bosco al Papa, Roma,13 de abril de 1880 . 
política establecida por el Gobierno. Tendría como sede a Carmen, que vendría a ser el centro de las misiones salesianas entre los indios, según el parecer de V.E. ... "Rogar a V.E de interponer sus buenos oficios ante el Gobierno a fin de que ayude con una anualidad pecuniaria para fundar y establecer el Vicariato, que se considera indispensable para asegurar el progreso civil y religioso de aquellas poblaciones. " 36

Con libertad y sin ataduras era como la Congregación tenía pensado implantar la Iglesia en la Patagonia. Por eso el planteo inicial de Don Bosco para la creación de un Vicariato a Propaganda Fide fue inmediato: "He expuesto (al Papa) mi pobre parecer sobre el modo que me parece que se puede dividir la Patagonia para atraer a sus habitantes al seno de la Iglesia"...Aqui me atendré solamente a lo que fue requerido por vuestra eminencia. Los tres vicariatos de la Patagonia: Parece que por ahora pueda bastar un sólo Vicariato apostólico en la Patagonia Septentrional y una Prefectura Apostólica en la Patagonia Meridional. ${ }^{37}$

La Patagonia Central no ha sido suficientemente explorada y la parte algo conocida está casi toda en manos de los disidentes (galeses).[...] El Vicariato apostólico del Carmen podría por ahora ocuparse del Vicariato Central, ir hasta las tribus que demoran en las cordilleras y, por medio de algunos sacerdotes $y$ de algunos catequistas provectos al servicio religioso de los pocos católicos que si bien estén mixturados con los heterodoxos, se conservan fieles a la Iglesia católica y piden de ser atendidos espiritualmente. [....] La Prefectura de la Patagonia Meridional encierra mayores dificultades por la rigidez del clima por las distancias de los lugares habitados y por los disidentes que se empeñan en penetrar. [....] Candidatos propuestos: Los candidatos propuestos: el doctor Juan Cagliero, Don Santiago Costamagna y don José Fagnano son tres individuos capaces de cumplir las funciones que se le encomienden. [...] El doctor Juan Cagliero para Vicario apostólico del Carmen, con jurisdicción sobre el Vicario central, hasta que este Vicariato pueda proveerse del pastor deseado. [...] Don Costamagna, a mi modo de ver, sería también un Vicario apostólico, como don Cagliero"[...] Don Fagnano es también muy apto para el Vicariato o Prefectura de la Patagonia Meridional."

Si bien la propuesta de Don Bosco apuntaba a tres vicariatos, la Santa Sede se inclinó por la erección de uno y una Prefectura apostólica. Faltaba el acuerdo de la otra parte, el Arzobispo de Buenos Aires, por pertenecer la Patagonia

36-Las misiones salesianas, reporte ante la Santa Sede. Memorias biográficas de San Juan Bosco, vol. XIV.p.629-30

37- Memorias biográficas de San Juan Bosco, vol.XIV. Memorial de Don Bosco a Propaganda Fide.

- Instituto de Historia Regional - Facultad de Ciencias Humanas - Universidad Nacional de La Pampa - 
a su jurisdicción y el Gobierno argentino, ya que "tanto él como el gobierno deben dar una respuesta a la Santa Sede" ${ }^{38 .}$

A fin de tantear la situación con el nuevo gobierno, distinto al de Avellaneda, Don Bosco envió a Roca una carta con la excusa de felicitarlo por su elección y le comunicó la posibilidad de la próxima erección de un Vicariato en la Patagonia: "El Santo Padre León XIII propone, en primer lugar, que la Patagonia sea erigida en Vicariato o prefectura apostólica. Con lo que después y aún inmediatamente se podrá fundar otra misión en Santa Cruz" ${ }^{13}$.

Si bien la respuesta de Roca no fue inmediata, en la entrevista con el Obispo Cagliero llevada a cabo en abril de 1886 sin mucho miramiento le objetó a éste "su calidad de Obispo en esta República (donde por ley fundamental del Estado nadie puede ascender a los primeros cargos ni a esta magistratura ni civil ni eclesiástica si no es nacido en el país)...y que el Papa no podía arbitrar sin el consenso y el acuerdo de su gobierno ${ }^{1140}$.

Los argumentos esgrimidos sobre el ejercicio del patronato y la condición de extranjeros de los Salesianos eran ineludibles y difíciles de objetar. De tal manera, Monseñor Cagliero respondió diplomáticamente que: "no tenía jurisdicción ordinaria, que era solamente un Obispo misionero, visitador de las casas salesianas, especialmente en la Patagonia; y que en los actos que pudiesen interesar al gobierno, yo entendía referirme a la autoridad del Arzobispo de Buenos Aires. "(en Bruno, 1981)

Monseñor Cagliero comprendía el riesgo que significaba poner todas las cartas sobre la mesa: "si hubiese presentado los documentos de la Santa Sede sobre el Vicariato, me había firmado rapidamente el pasaporte como al Delegado apostólico Monseñor Matera. "(en Bruno, 1981) La conversación giró sobre las misiones y los trabajos civilizadores de los misioneros. Cagliero logró hábilmente ganarse la simpatía y confianza de Roca y le hizo prometer que reanudaría las relaciones con la Santa Sede.

La comunicación al Arzobispo tampoco tuvo buena acogida. Si bien Aneiros siempre había sido bien dispuesto con los Salesianos, y él mismo les había ofrecido la misión del Carmen, evidentemente el asunto se le fue de sus manos y tuvo temor de que los Salesianos desmembraran una parte de su diócesis.

38- Epistolario di S.Giovanni Bosco. TIII, Lettera 2229, Carta de Don Bosco a Costamagna, 1 de octubre de 1881. Traducción propia del italiano.

39-AGN, Sala VII, Leg. 13 Correspondencia recibida. Carta de Don Bosco a Roca, Turín,10 de noviembre de 1880 .

40- Archivo Secreto de Propaganda Fide, Roma, Scritture riferite nei congressi, transcripción completa en italiano en BRUNO, Los salesianos...p.355. 
En tanto se sucedían los enfrentamientos en la Argentina, Don Bosco había logrado su propósito ante la Santa Sede y no iba a presenciar las consecuencias que sus planes vicariales, fruto de la concepción del indio y su evangelización, tuvieron en la lejana Patagonia.

\section{Conclusiones.}

La preocupación que generaron los espacios poblados por indios provocaron una suerte de conciencia territorial de la que se apropiaron tanto el Estado como la Iglesia nacional. La falta de presupuesto para llevar a cabo la ocupación de estos territorios y la incorporación de sus habitantes dificultaron enormemente la tarea. Por otro lado, el Estado a través de la Constitución estaba obligado a hacerse cargo de la incorporación social y religiosa de los indios que habían sobrevivido al exterminio.

La Iglesia tampoco estaba en mejores condiciones: la falta de clero y la escasez de vocaciones concentraban el poco personal en los centros más poblados. Los territorios patagónicos se encontraban a grandes distancias de la sede Arzobispal y por si esto fuera poco, eran políticamente débiles ante la presión del ejercicio del patronato y las relaciones interrumpidas entre el Estado argentino y el Vaticano.

La afortunada coincidencia entre la búsqueda de misioneros del cónsul argentino en Italia y los planes de evangelización de la Patagonia ideados por Don Bosco, parecían haber solucionado los problemas mencionados. Sin embargo, en el momento en que el Estado, la Iglesia y los salesianos decidieron ocupar el espacio patagónico los enfrentamientos no se hicieron esperar.

Cada uno de ellos tenía un plan y un interés concreto en la organización de este espacio. El Estado no quería dejar de ejercer el patronato como modo de presión hacia la Iglesia, teniendo a su cargo la organización administrativa de los nuevos territorios y sometiendo bajo su jurisdicción a cualquier otro tipo de organización que allí se desarrollara.

La Iglesia argentina, en una situación de debilidad, quería mantener sus relaciones intactas con el Vaticano y con los salesianos sin contrariar al Estado, de quien dependía política y económicamente. Además el espacio ocupado por los salesianos cercenaba el poder del Arzobispado porteño y dejaba bajo el control de una congregación religiosa poderosa un territorio vasto en donde todo estaba por hacerse.

Los salesianos buscaban un territorio de misión en el que pudieran desarrollarse sin ataduras y sin dependencias de la Iglesia metropolitana y del 
patronazgo del Estado argentino. Un territorio propio, en el que los misioneros dependieran directamente de la Congregación y del Vaticano.

Los intereses de cada parte se enfrentaron inevitablemente, pues la raíz del conflicto iba más allá de los conflictos puntuales. En el fondo, la concepción misma del territorio patagónico y sus habitantes originarios era el meollo de la situación.

Para el Estado la Patagonia era un territorio "vacío" que debía formar parte de la Nación sin importar el "modus operandi". Para la Iglesia metropolitana, era una jurisdicción eclesiástica que nacía como territorio misionero y al cual se incorporaban "infieles" que debían ser "civilizados y evangelizados".

Para Don Bosco, la Patagonia era la "tierra prometida", fruto de una visión y un Ilamado concreto de Dios a la Congregación Salesiana. Esa tierra "virgen" era la posibilidad de crear un espacio misionero autónomo que protegiera a sus habitantes originarios, porque para Don Bosco, el "infiel" era básicamente educable y redimible.

El Vicariato apostólico reunía para Don Bosco estos requisitos enunciados: debía ser designado directamente por la Santa Sede, evitando así la injerencia del Estado argentino y la Iglesia. Por ser una jurisdicción ordinaria para regir las cristiandades en territorios donde aún no había sido introducida la jerarquía eclesiástica, permitía el monopolio de la congregación religiosa en estas tierras. $Y$ finalmente al estar gobernadas por un Obispo titular posibilitaba el nombramiento de un Obispo salesiano, instalando una jerarquía perteneciente a la Congregación.

La aprobación del Vicariato apostólico provocó reacciones que fueron más allá del Rectorado Mayor de Bosco y pusieron en peligro la continuidad de la misión salesiana. Sin embargo, los condicionantes económicos del Estado y de personal de la Iglesia, jugaron a favor de la Congregación que supo hábilmente negociar, no sólo su permanencia en la Patagonia sino su perpetuidad misionera aunque eso, le valiera descender de Vicariato a Vicarías foráneas. El tiempo y las circunstancias jugaron a favor de los "hijos" de Don Bosco, que pudieron mantener no sólo misioneros sino Obispos salesianos en la Patagonia, más allá de los primeros gobiernos diocesanos.

\section{Referencias bibliograficas citadas}

*AUZA, Néstor Tomás (1979). "El crecimiento de la conciencia territorial argentina". Revista Nacional de Cultura, (Buenos Aires), 5.

*AUZA, Néstor Tomás(1980). "La ocupación del espacio vacío: de la frontera 
interior a la frontera exterior, 1876-1910".En: GALLO, Ezequiel y FERRARI, Gustavo(comp). La Argentina del 80 al centenario. Buenos Aires, Sudamericana. *BELZA, Juan (1979) "La expedición al desierto y el amanecer de las misiones salesianas en la Patagonia". En:(BELZA, Juan y otros, La expedición al desierto y los Salesianos, Buenos Aires, Don Bosco.

*BRUNO, Cayetano (1981). Los Salesianos y las Hijas de María Auxiliadora en la Argentina. Buenos Aires, Instituto Salesiano de Artes gráficas. Vol.1.

*COPELLO, Santiago. (1944). El primer capellán del Chubut, canónigo Francisco Vivaldi. Buenos Aires, EMECE.

*NICOLETTI, María Andrea (1994). La Evangelización norpatagónica colonial. Informe al CONICET, Beca de Perfeccionamiento.

*NICOLETTI, María Andrea (1995). La Evangelización del Neuquén en la época nacional. Informe al CONICET, Beca de Perfeccionamiento.

*NICOLETTI, María Andrea (1996).La evangelización en Río Negro, Chubut y Santa Cruz. Informe al CONICET. Beca Post-doctoral.

*NICOLETTI, María Andrea (1997). La formación de la Iglesia patagónica y su relación con el Estado Nacional (fines del siglo XIX a mediados del siglo XX"). Informe de investigación para el CONICET.

*da SILVA FERREIRA, Antonio (1995). Patagonia. Relata e mito nell'azione missionaria salesiana, Roma, Libreria Ateneo Salesiano.

*da SILVA FERREIRA, Antonio.(1996) "Due sogni sulle missione della Patagonia e dell'America Latina". Ricerche Storiche salesiane,(Roma) (enerojunio).

\section{Fuentes documentales citadas}

Fuentes editas

*TERRITORIOS NACIONALES. Leyes y decretos sobre su administración y resoluciones varias aplicables en los mismos. Buenos Aires, 1914.

*MEMORIAS DEL MINISTERIO DEL INTERIOR, (1912).Informe de la Dirección general de Territorios Nacionales.

*BOSCO, Juan(1996). La Patagonia y las tierras australes del continente americano (1876), Bahía Blanca, Archivo Histórico salesiano de la Patagonia.

*D'ORBIGNY, Alcides (1944). El hombre americano, Buenos Aires, Futuro.

*BOLETÍN SALESIANO, julio 1890.

*CERIA, Eugenio (1986). Memorias Biográficas de San Juan Bosco. Madrid. Central catequística salesiana. Vol.XIV.

*CERIA, Eugenio (1955).Epistolario di S. Giovanni Bosco. Torino. Societá editrice internazionales. Vol.III y Vol.IV. 


\section{Fuentes inéditas}

*ARCHIVO GENERAL DE LA NACIÓN, Ministerio del Interior, legajo 14 exp.5698. Sala VII, Legajo 13 Correspondencia recibida. Carta de Don Bosco a Roca, Turín, 10 de noviembre de 1880.

*ARCHIVO DEL MINISTERIO DE RELACIONES EXTERIORES Y CULTO, Caja 10, Culto. Antecedentes y resoluciones sobre Culto. Caja 18 (640). Culto. 1897. Leg.3. Carta al Cardenal Rampolla, secretario de Estado de la santa Sede de Carlos Calvo. Roma, diciembre 7 de 1896. Caja 18 (640). Culto. 1897. Correspondencia entre Carlos Calvo y el Cardenal Rampolla.1897.Decreto del Excmo. Gobierno Nacional sobre la erección de las diócesis. Auto de erección de las diócesis firmado por el Arzobispo de Buenos Aires. Uladislao Castellano. Caja 18 (640). 1897. Culto.leg.33.

*ARCHIVO CENTRAL SALESIANO (BUENOS AIRES), Caja 152, Personas, Padre Vespignani, Carta del Padre Vespignani al Internuncio M. Locatelli,7 de agosto de 1909.

Caja 59, Monseñor Espinosa. Auto del 9 de mayo de 1911.

Caja 152.62.P. Vespignani, Correspondencia. Memoria sobre Vicariato. 